\title{
Singapore Basic Cardiac Life Support and Automated External Defibrillation Guidelines 2021
}

\author{
Swee Han $\underline{L i m}^{1}$, fRCSEd, fRCPEd, Tek Siong $\underline{\mathrm{Chee}^{2}}$, MBBS, MMed, Fong Chi Wee ${ }^{3}$, MSH, MEd, Siew Hong $\underline{\operatorname{Tan}^{4,5}}$, BN, MNS,
} Jun Hao Loke ${ }^{6}$, BSc, Benjamin Sieu-Hon Leong ${ }^{7}$, MBBS, MRCSEd

\begin{abstract}
Basic Cardiac Life Support and Automated External Defibrillation (BCLS+AED) refers to the skills required in resuscitating cardiac arrest casualties. On recognising cardiac arrest, the rescuer should call for '995' for Emergency Ambulance and immediately initiate chest compressions. Good-quality chest compressions are performed with arms extended, elbows locked, shoulders directly perpendicular over the casualty's chest, and the heel of the palm placed on the lower half of the sternum. The rescuer compresses hard and fast at 4-6 cm depth for adults at a compression rate of 100-120 per minute, with complete chest recoil after each compression. Two quick ventilations of $400-600 \mathrm{~mL}$ each can be delivered via a bag-valve-mask after every 30 chest compressions. Alternatively, a trained, able and willing rescuer can provide mouthto-mouth ventilation. Cardiopulmonary resuscitation should be stopped only when the casualty wakes up, the emergency team takes over care, or when an automated external defibrillator prompts for heart rhythm analysis or delivery of a shock.
\end{abstract}

Keywords: automated external defibrillation, basic cardiac life support, cardiopulmonary resuscitation, chest compressions

\section{INTRODUCTION}

Basic Cardiac Life Support and Automated External Defibrillation (BCLS+AED) refers to the recognition of sudden cardiac arrest (SCA), calling for help by dialling '995' for Emergency Medical Service (EMS), i.e. Singapore Civil Defence Force (SCDF) emergency ambulance, supporting the circulation by performing chest compressions, maintaining the airway and supporting breathing without the use of equipment other than personal protective devices, as well as the use of an automated external defibrillator. These skills could be used by a layperson or a healthcare provider for both in-hospital and out-of-hospital settings.

The majority of SCAs occur in the community (i.e. out-ofhospital setting). The success of the chain of survival depends on the first responder, who is often a layperson. The goal of cardiopulmonary resuscitation (CPR) training is to ensure that participants 'can and will do' CPR when needed. CPR guidelines must be scientific and easy to follow to improve skills retention, decrease the fear of imperfect CPR performance and increase willingness to perform CPR.

In 2020, the International Liaison Committee on Resuscitation (ILCOR) reviewed and updated the consensus document on the science based on the latest developments in research. The International Consensus on Cardiopulmonary Resuscitation and Emergency Cardiovascular Care Science with Treatment Recommendations (CoSTR) was published in the journals Circulation $^{(1)}$ and Resuscitation ${ }^{(2)}$ in October 2020. The various resuscitation councils then formulated their own guidelines ${ }^{(3,4)}$ based on the 2020 international CoSTR. The following document spells out the Singapore guidelines, as drawn up by the BCLS+AED subcommittee of the Singapore Resuscitation and First Aid Council (SRFAC).

\section{HIGHLIGHTS OF CHANGES IN BCLS+AED GUIDELINES IN 2021}

There are no major changes in the SRFAC 2021 guidelines when compared to the guidelines published by the National Resuscitation Council, Singapore, in 2017 regarding how CPR is performed, except that the BCLS+AED subcommittee recommends against the placing of a casualty with return of spontaneous circulation (ROSC) in a recovery position, as it may hinder detection of a subsequent cardiac arrest. An additional highlight is the emphasis to follow the dispatcher's instructions for the lone rescuer to stay with the casualty while additional rescuers are contacted to collect a nearby AED. The definition of paediatric age has also been revised as persons aged below 12 years, while adults are defined as persons aged above 12 years. More details can be found in the paediatric life support article in this issue of the journal. ${ }^{(5)}$

\section{Recognition of cardiac arrest}

Studies have shown that gasping is common (up to $40 \%$ of cases) in the initial phase of SCA. ${ }^{(6)}$ Laypersons or healthcare providers should be taught to recognise gasping as cardiac arrest and not normal breathing, and to begin CPR immediately. A video comparing gasping and normal breathing can be found on SRFAC's website (https://srfac.sg/videos/).

When a call is received by SCDF 995, the presence of nonresponsiveness and absence of normal breathing should be recognised as cardiac arrest. Callers may have difficulty identifying

\footnotetext{
${ }^{1}$ Department of Emergency Medicine, Singapore General Hospital, ${ }^{2}$ Chee Heart Specialists Clinic, Parkway East Medical Centre, ${ }^{3}$ Nursing Service, Tan Tock Seng Hospital, ${ }^{4}$ School of Health and Social Sciences, Nanyang Polytechnic, ${ }^{5}$ Lee Kong Chian School of Medicine, Nanyang Technological University, ${ }^{6}$ Singapore Resuscitation and First Aid Council, Unit for Pre-hospital Emergency Care, ${ }^{7}$ Emergency Medicine Department, National University Hospital, Singapore

Correspondence: Prof Lim Swee Han, Senior Consultant, Department of Emergency Medicine, Singapore General Hospital, Outram Road, Singapore 169608. lim.swee.han@singhealth.com.sg
} 
this if the casualty is breathing. SCDF call-takers will instruct the caller to detect breathing by placing a hand on the casualty's mid-abdomen to feel for the rise and fall of the abdomen. ${ }^{(7)}$ If in doubt, the casualty should be presumed to be in cardiac arrest.

At the onset of cardiac arrest, a brief duration of seizure may be observed. After the seizure has stopped, it is important to immediately check for responsiveness and normal breathing; if absent or unsure, call for help and start CPR. ${ }^{(4)}$

\section{Dispatcher-assisted CPR}

Dispatcher-assisted CPR (DACPR) increases the bystander CPR rate and improves the survival rate of cardiac arrest. ${ }^{(8)}$ When the casualty satisfies telephone criteria for cardiac arrest (unresponsive, absent breathing) or is presumed to be in cardiac arrest (unresponsive, abnormal breathing), the call-taker should direct the caller to stay on the line and provide instructions regarding the performance of CPR. DACPR instructions should be for chest compression-only CPR for adults and CPR with ventilation for paediatric arrests. In addition, a mobile application known as 'myResponder' will activate nearby Community First Responders (CFRs) within a 400-m radius of the incident location and guide the responder to fetch the nearest AED while on the way to the scene and assist in CPR. ${ }^{(8)}$

\section{Removal of pulse check for lay rescuers}

Pulse check is a difficult technique to master for both laypersons and healthcare providers, ${ }^{(9)}$ and should not be taught to laypersons. ${ }^{(10-12)}$ Training centres, if teaching healthcare providers the pulse check as an additional tool for determination of cardiac arrest and when deciding to start CPR, should use mannequins that can simulate the presence or absence of a pulse. The healthcare provider should take no more than ten seconds to check for normal breathing and pulse, and should start chest compressions if there is no normal breathing or definite absence of a pulse.

\section{Technique of chest compression Landmark for chest compression}

Since 2016, it is recommended that the rescuer be taught and shown the location of the landmark for chest compression - the lower half of the sternum and centre of the chest on the mannequin. ${ }^{(12)}$

\section{Depth and rate of chest compression}

A large study of out-of-hospital cardiac arrest (OHCA) adult casualties $(\mathrm{n}=9,136)$ treated by EMS providers found that the maximum survival was with a compression depth interval of 40.3-55.3 mm (peak $45.6 \mathrm{~mm}){ }^{(13)}$ In an observational study of 170 casualties, injuries were reported in $28 \%, 27 \%$ and $49 \%$ of casualties who had compression depths of $<5 \mathrm{~cm}, 5-6 \mathrm{~cm}$ and $>6 \mathrm{~cm}$, respectively. ${ }^{(14)}$ Considering that this study was carried out in Scandinavia, compression of the chest deeper than $5 \mathrm{~cm}$ may not be necessary in our population. In addition, a considerable proportion of our doctors and nurses may not be able to compress more than $5 \mathrm{~cm}$ in depth due to their small body size. ${ }^{(15)}$ Data from a large study $(n=10,371)$ on adults with OHCA treated by EMS providers found that after adjustments for chest compression depth, compression rates of 100-120 per minute were associated with higher survival rates. ${ }^{(16)}$
Therefore, SRFAC recommends a chest compression depth of about $5 \mathrm{~cm}$ (i.e. $4-6 \mathrm{~cm}$ ) during manual CPR and a chest compression rate of 100-120 per minute.

\section{Chest compression-only CPR}

Most sudden OHCAs occur in adults and are of a cardiac origin. ${ }^{(17,18)}$ About $70 \%-80 \%$ of OHCA casualties initially have ventricular fibrillation (VF); ${ }^{(19,20)}$ thus, rescue breaths are not as important as chest compressions due to adequate oxygen level in the blood for the first few minutes after cardiac arrest. ${ }^{(21)}$

Two before-and-after implementation observation studies have demonstrated an improved rate of survival in adult OHCA after the implementation of chest compression-only CPR (CCC) in the community (Arizona, USA and Japan). ${ }^{(19)}$ In Arizona, the survival rate of adult OHCA of cardiac aetiology was $7.8 \%$ for those who received conventional CPR (CVC), $13.3 \%$ for those who received CCC and $5.2 \%$ for those who received neither. There was a significant increase in bystander CPR rate, from 28.2\% in 2005 to $39.9 \%$ in 2009 , and an increase in the proportion of bystanders performing CCC vs. CVC (from $19.6 \%$ to $75.9 \%$ ). ${ }^{(6)}$

In one local study, ${ }^{(22)}$ it was apparent that during a six-month post-training test, $14.9 \%$ of participants who were trained in CCC pretended to do mouth-to-mouth (MTM) ventilation. Only $14.9 \%$ were able to perform $\geq 5$ effective ventilations ( $\geq$ $400 \mathrm{~mL}$ ), and only $3.7 \%$ were able to perform $\geq 10$ effective ventilations in five minutes. Most participants who were trained in MTM ventilation were unwilling or unable to perform effective MTM ventilations six months after training. Interrupting chest compression to perform ineffective MTM ventilation is detrimental to resuscitation.

Therefore, SRFAC recommends that CPR training for lay rescuers should focus on recognising cardiac arrest, calling for an ambulance and delivering good-quality manual chest compression. Since March 2020, SRFAC has transited to teaching healthcare providers the use of bag-valve-mask (BVM) instead of MTM ventilation due to the COVID-19 pandemic.

\section{Implementation of PAD programmes}

ILCOR COSTR 2020 strongly recommends the implementation of Public Access Defibrillator (PAD) programmes based on low certainty evidence. ${ }^{(2,4)}$ Despite the heterogeneity of the study methods, these studies showed that the implementation of PAD programmes improve OHCA survival. The location of OHCA in these studies included residential communities, airports, subways, casinos and sports facilitites. Locally, the Singapore Heart Foundation and SCDF jointly produced an AED owner's guide (https://www.myheart.org.sg/wp-content/uploads/2019/01/ AED-guide-web.pdf), which provides basic information regarding the use of AEDs, training, installation and maintenance.

\section{SEQUENCE OF ADULT ONE-RESCUER CPR AND USE OF AED}

The recommended sequence of adult one-rescuer $\mathrm{CPR}$ and use of AED, using the mnemonic 'DRSABC' (Fig. 1), is as follows. Table I shows a summary of CPR in the different age groups. 


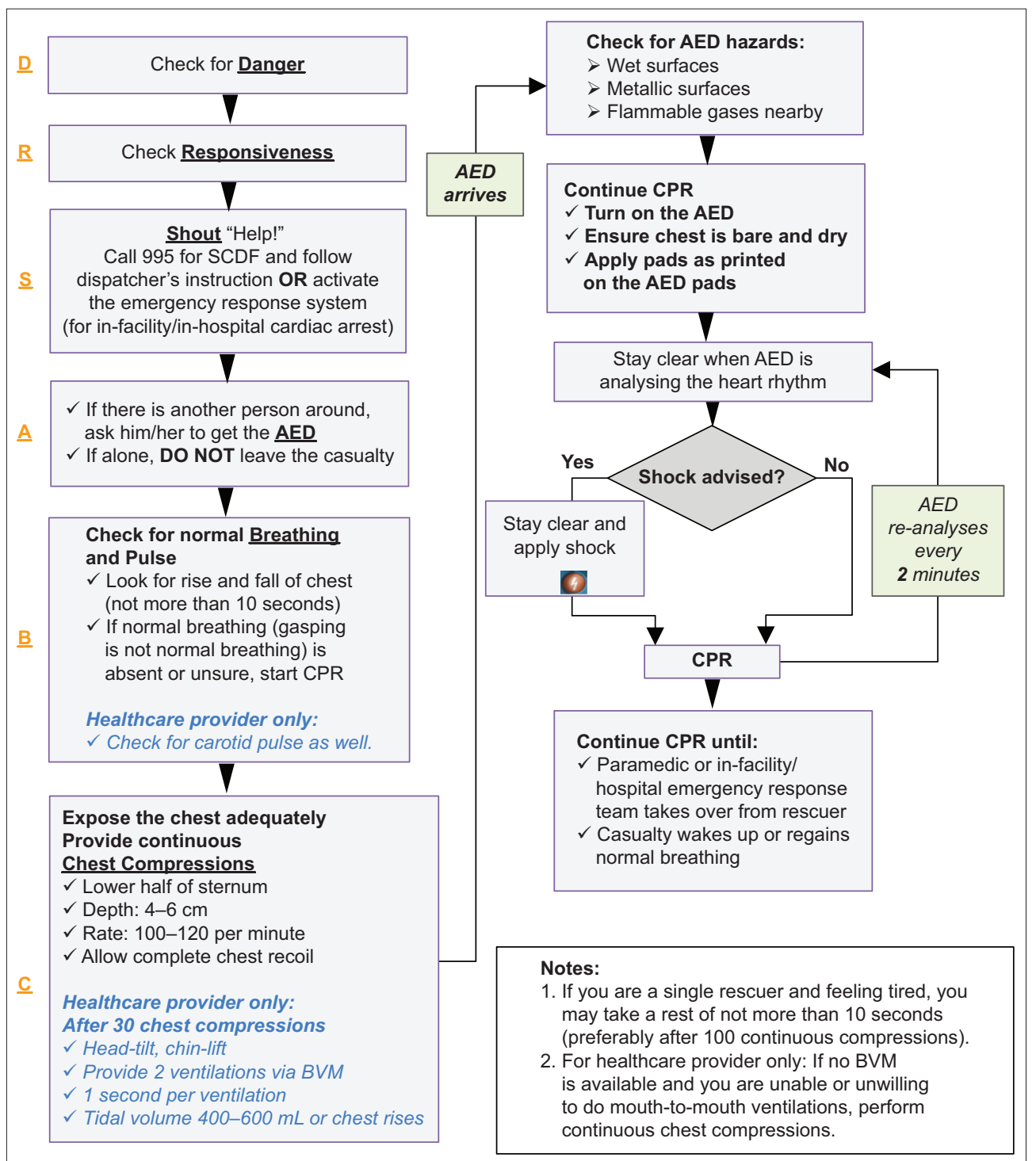

Fig. 1 Algorithm for one-rescuer cardiopulmonary resuscitation (CPR) and use of automated external defibrillation (AED). BVM: bag-valve-mask; SCDF: Singapore Civil Defence Force

1. (D) Check for danger: ensure that the rescuer operates in a safe environment. Resuscitation should start where the casualty is found, unless the site is unsafe or unconducive (e.g. roads that are still open to traffic, burning building, etc); then the casualty should be removed to a safe, flat and open space as soon as possible.

2. (R) Check for responsiveness: the rescuer should tap the casualty's shoulders firmly and ask loudly: "Hello! Hello! Are you okay?"

3. (S) If unresponsive: shout to get help from bystanders to call 995 for SCDF or activate the emergency response system (for in-facility/in-hospital cardiac arrest). If alone, use a handphone to call 995 for SCDF and put the phone on speaker mode. The SCDF call-taker can help a lay rescuer recognise cardiac arrest. Once established, the call-taker will guide the rescuer to begin CPR by providing instructions on how to perform chest compressions via the telephone. If a lone rescuer finds an unresponsive casualty in a remote area with no accessibility to activate EMS, the lone rescuer needs to assess the casualty's responsiveness and breathing, and if absent, commence chest compressions immediately and continue for at least two minutes before leaving the casualty to seek help.

4. (A) Send someone to get an AED if within a 60-second walking distance. The SCDF dispatcher may be able to locate the nearest AED and summon help from nearby CPRtrained rescuers. However, if you are the lone rescuer, do not leave the casualty.

5. (B) Look for normal breathing for up to ten seconds. Gasping is not considered normal breathing (see https://srfac.sg/ videos/ for a video of the difference between gasping and normal breathing).

a) Checking for normal breathing should not take more than ten seconds.

b) Checking of carotid pulse and breathing (not more than ten seconds) should be done by trained healthcare providers.

c) If unsure of the presence of normal breathing (and pulse for trained healthcare providers only) within ten seconds, start chest compressions. 
Table I. Summary of cardiopulmary resuscitation (CPR) for the different age groups.

\begin{tabular}{|c|c|c|c|}
\hline CPR summary for cardiac arrests & $\begin{array}{l}\text { Adult and adolescent } \\
>12 \mathrm{yr}\end{array}$ & Child (1-12 yr) & Infant $(<1$ yr) \\
\hline Check for danger & \multicolumn{3}{|c|}{ Ensure rescue scene is safe } \\
\hline Check for responsiveness & \multicolumn{2}{|c|}{ Tap the casualty's shoulders to get a response } & $\begin{array}{l}\text { Tap the casualty's shoulders and the infant's } \\
\text { feet to get a response }\end{array}$ \\
\hline Shout for help & \multicolumn{3}{|c|}{$\begin{array}{l}\text { Shout for help and call ambulance '995', put on speaker phone mode and } \\
\text { follow dispatcher's instructions and/or activate in-facility/in-hospital emergency response } \\
\text { system }\end{array}$} \\
\hline Get an AED & \multicolumn{3}{|c|}{$\begin{array}{l}\text { Send someone to get an AED if there is one within a 60-second walking distance. If you are the lone } \\
\text { rescuer, do not leave the casualty }\end{array}$} \\
\hline Check for breathing & \multicolumn{3}{|c|}{ Look for normal breathing (If not breathing, gasping/agonal breathing) - proceed to step C } \\
\hline (recognition of cardiac arrest) & \multicolumn{2}{|c|}{$\begin{array}{l}\text { Pulse check performed by HCP: no definite pulse } \\
\text { within } 10 \text { seconds - proceed to step C } \\
\text { (adult/child: carotid) }\end{array}$} & $\begin{array}{l}\text { Pulse check performed by HCP: no definite } \\
\text { pulse within } 10 \text { seconds or pulse rate } \\
<60 / \text { min - proceed to step C (infant: brachial) }\end{array}$ \\
\hline Compression landmarks & \multicolumn{2}{|c|}{ Lower half of sternum } & $\begin{array}{l}\text { Lower half of sternum (1 finger's breadth } \\
\text { immediately below inter-mammary line) }\end{array}$ \\
\hline Compression method & \multicolumn{2}{|c|}{ Heel of 1 hand with other hand on top } & $\begin{array}{l}2 \text { thumb encircling hands (or ring and middle } \\
\text { fingers for lay rescuers) }\end{array}$ \\
\hline $\begin{array}{l}\text { Compression depth } \\
\text { (push hard with full recoil) }\end{array}$ & $4-6 \mathrm{~cm}$ & $4-5 \mathrm{~cm}$ & $3-4 \mathrm{~cm}$ \\
\hline Compression rate & & $100-120$ & \\
\hline \multicolumn{4}{|l|}{ Compression-ventilation ratio } \\
\hline $\begin{array}{l}\text { Trained, willing and able to } \\
\text { provide MTM ventilations }\end{array}$ & \multicolumn{3}{|c|}{$\begin{array}{l}30: 2 \text { ( } 1 \text { or } \geq 2 \text { rescuers) } \\
1 \text { second per ventilation - observe for chest rise }\end{array}$} \\
\hline HCP (using BVM) & $30: 2$ ( 1 or 2 rescuers) & \multicolumn{2}{|c|}{$30: 2$ (1 rescuer), $15: 2$ ( $\geq 2$ rescuers) } \\
\hline $\begin{array}{l}\text { Untrained, unable or unwilling to } \\
\text { perform ventilations }\end{array}$ & \multicolumn{3}{|c|}{ Continuous high-quality chest compressions } \\
\hline Rescue breathing & $\begin{array}{l}1 \text { ventilation every } \\
5 \text { seconds } \\
(12 / \mathrm{min})\end{array}$ & $\begin{array}{l}1 \text { ventilation every } \\
3 \text { seconds } \\
(20 / \mathrm{min})\end{array}$ & $\begin{array}{l}1 \text { ventilation every } 2 \text { seconds } \\
\qquad(30 / \mathrm{min})\end{array}$ \\
\hline Use of AED & $\begin{array}{l}\text { Use adult defibrillation } \\
\text { pads }\end{array}$ & $\begin{array}{l}\text { Under } 25 \mathrm{~kg} \text {, use child } \\
\text { defibrillation pads if } \\
\quad \text { available }\end{array}$ & $\begin{array}{l}\text { Manual defibrillators preferred, but if } \\
\text { unavailable, use child pads }\end{array}$ \\
\hline
\end{tabular}

AED: automated external defibrillator; BVM: bag-valve-mask; HCP: healthcare provider; MTM: mouth-to-mouth

6. (C) The technique of chest compressions

a) Site of compression should be at the centre of the chest at the lower half of the sternum (breastbone) (Fig. 2).

- Ensure adequate exposure of the chest.

- Kneel by the side of the casualty.

- Place the heel of one hand on the lower half of the sternum (breastbone).

- Place the heel of the second hand on top of the first.

- Interlace the fingers of both hands and lift the fingers off the chest wall.

- Straighten both the elbows and lock them into position.

- Position the shoulders directly over the casualty's chest. Use the body weight to compress the casualty's breastbone.

b) Depth of chest compression for adults must be $4-6 \mathrm{~cm}$.

c) The compression rate is 100-120 per minute.

d) Ensure complete recoil of the chest wall after each compression. If tired after 100 compressions, rescuer can take up to ten seconds of rest and then resume compressions. ${ }^{(23)}$ e) Loud counting of the compressions should be encouraged: $1 \& 2 \& 3 \& 4 \& 5 \&, 1 \& 2 \& 3 \& 4 \& 10 \&$, $1 \& 2 \& 3 \& 4 \& 15,1 \& 2 \& 3 \& 4 \& 20,1 \& 2 \& 3 \& 4 \& 25$, $1 \& 2 \& 3 \& 4 \& 30 \ldots$ up to 100 .

f) Healthcare providers only: Perform head-tilt-chinlift and provide two ventilations (via BVM, one second per breath, tidal volume $400-600 \mathrm{~mL}$ or just enough to produce chest rise) after every 30 chest compressions. If BVM is not available, and the healthcare provider is trained, able and willing to provide MTM ventilation, he or she may proceed with MTM ventilations. Otherwise, resume chest compressions only, taking ten seconds of rest after 100 compressions before resuming compressions. For more details on head-tilt-chin-lift and MTM ventilations, refer to the SRFAC BCLS+AED manual. ${ }^{(24)}$

g) Continue performing CPR until:

- The paramedic takes over from the rescuer; or

- AED prompts to analyse the casualty, is charging or when shock is to be delivered; or 

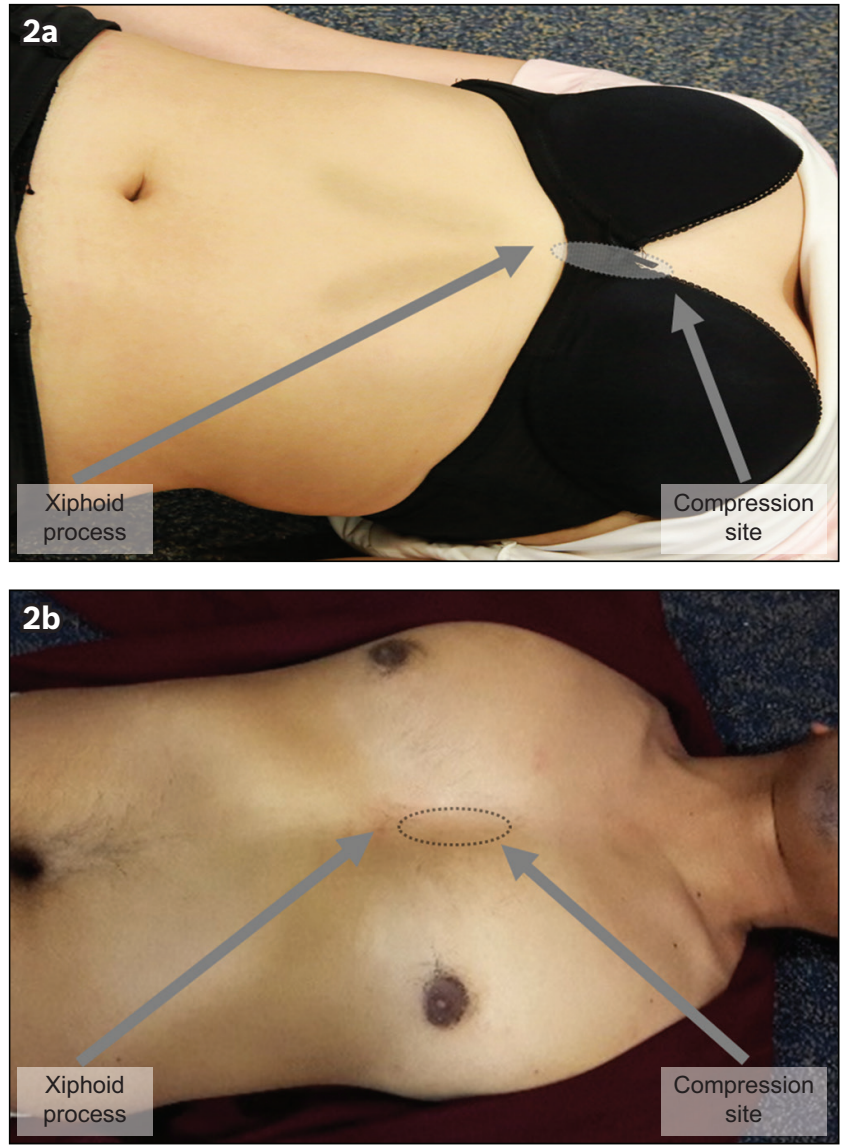

Fig. 2 Photographs show the site of compression for (a) female and (b) male casualties.

- The casualty wakes up or regains normal breathing.

- Healthcare providers who are trained and confident in pulse check should check the pulse after at least five cycles of 30 compressions to two ventilations (done via BVM). Checking of pulse should not take more than ten seconds. If unsure of the presence of a pulse by the end of ten seconds, the rescuer should resume CPR.

7. Use of AEDs

a) Before using an AED, rescuers have to ensure that the casualty is not lying on a metallic and/or wet surface, or in a space with flammable gases.

b) If the AED is being prepared by another rescuer, the first rescuer should continue chest compressions and should not be interrupted unless necessary.

c) The AED should be turned on once it has been placed at the side of the casualty to allow the AED to provide instructions.

d) The casualty's chest should be exposed to enable the application of the defibrillation pads in accordance with the instructions printed on defibrillation pads; the pads should be applied on bare, dry chest - one below the right clavicle and the other on the lateral side of the chest of the left breast (apex of the heart) (Fig. 3).

- Wipe dry the casualty's chest if it is wet.

- If needed, shave off any chest hair at the pads' application sites and shift any jewellery away from the chest.
- Remove any medication patches (e.g. glycerin trinitrate patches) and wipe off the residue.

- A defibrillation pad should be placed about four fingers' breadth away from a pacemaker (take special note if pacemaker is found to be implanted under the right clavicle/right chest).

e) Once the AED prompts to analyse the casualty's heart rhythm, chest compressions should be paused.

- If 'no-shock' is advised, immediately resume chest compressions.

- If 'shock' is advised, the AED will charge up automatically. No one should be in contact with the casualty. Press the 'shock' button and immediately resume chest compressions after the shock has been delivered.

8. The AED will reanalyse the heart rhythm every two minutes and prompt the rescuer not to touch the casualty. The rescuer should follow step 7e above.

9. The lay rescuer should continue performing continuous chest compressions until the emergency medical team arrives to take over, or the AED prompts the rescuer not to touch the casualty, or the casualty starts breathing normally.

10. Healthcare providers who are trained and confident in pulse check should check the pulse when the AED prompts to analyse the casualty's heart rhythm every two minutes, or when breathing or movement is detected. Checking of pulse should not take more than ten seconds. If unsure of the presence of a pulse by the end of ten seconds, the rescuer should resume CPR. If the pulse is present but not breathing, start rescue breathing.

\section{Two-person CPR}

When there is more than one trained rescuer, the second rescuer should:

1. Call 995 for SCDF.

2. Get the nearest AED.

3. Take turns to perform chest compressions after every two minutes, as fatigue would otherwise set in. The changeover should involve minimal interruption to chest compressions.

\section{CPR in special settings}

Resuscitation training should simulate the environment that rescuers may find themselves in. For example, healthcare providers should practise resuscitation skills on mannequins on a trolley bed and stand on a step stool at the side of the trolley bed. This is to ensure the elbows can be straightened to facilitate chest compressions. ${ }^{(25)}$

Although we are taught to perform chest compression by kneeling at the side of the casualty, there may be specific circumstances involving narrow alleys, walkways or corridors where the rescuer may have to perform chest compressions by positioning himself over the head instead of the usual lateral side (Fig. 4). ${ }^{(26)}$ In the case of a passenger aircraft, a rescuer should kneel in the leg-space in front of the aisle seats to perform chest compressions if the casualty cannot be transferred within a few seconds to an area with adequate floor space such as the galley. ${ }^{(27)}$ 


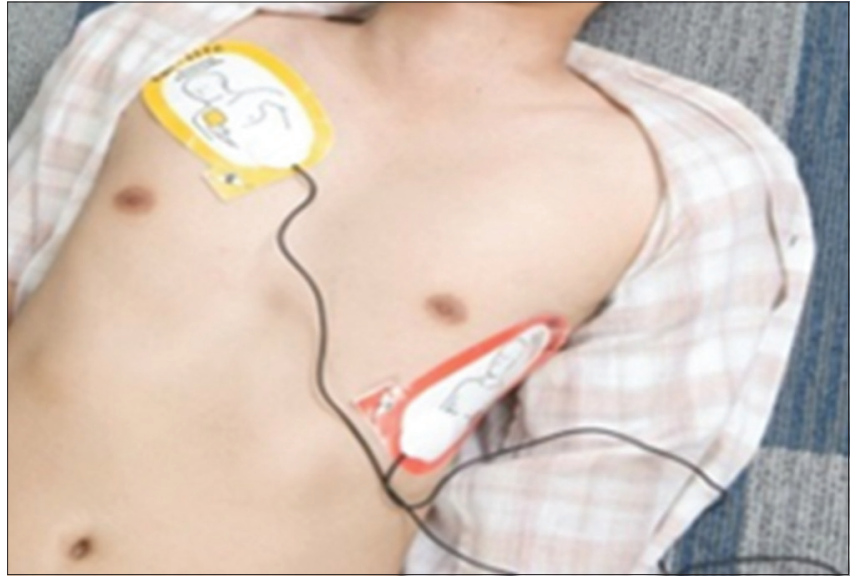

Fig. 3 Photograph shows the application of automated external defibrillation pads.

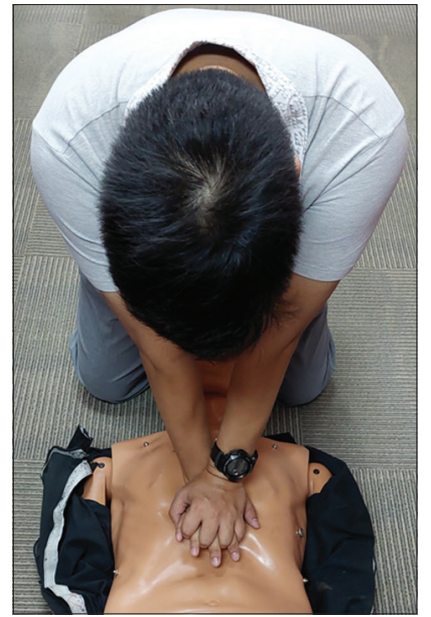

Fig. 4 Photograph shows overhead cardiopulmonary resuscitation.

The above are not definitive guidelines to resuscitation in tight spaces but can be taken as a reference should anyone be caught in similar situations.

\section{Recommendation against recovery position for cardiac arrest casualties with ROSC}

The SRFAC no longer recommends placing of cardiac arrest casualties with ROSC in the recovery position due to concerns that it may hinder the detection of subsequent cardiac arrest prior to the arrival of the EMS. ${ }^{(4,28,29)}$ Recovery position should be reserved for unresponsive casualties with spontaneous breathing, who are affected by conditions that are non-cardiac arrest in nature, such as stroke, hypoglycaemia or fainting. This is described in the first aid article published in the same issue of the journal. ${ }^{(30)}$

\section{Duration of retraining cycle}

There is evidence of skills decay within 12 months after CPR training. ${ }^{(25)}$ There is also evidence that frequent training improves CPR skills, responder confidence and willingness to perform CPR. Although the SRFAC retains the two-yearly recertification guidelines for BCLS+AED courses, individuals who are likely to encounter cardiac arrest casualties should consider more frequent retraining.

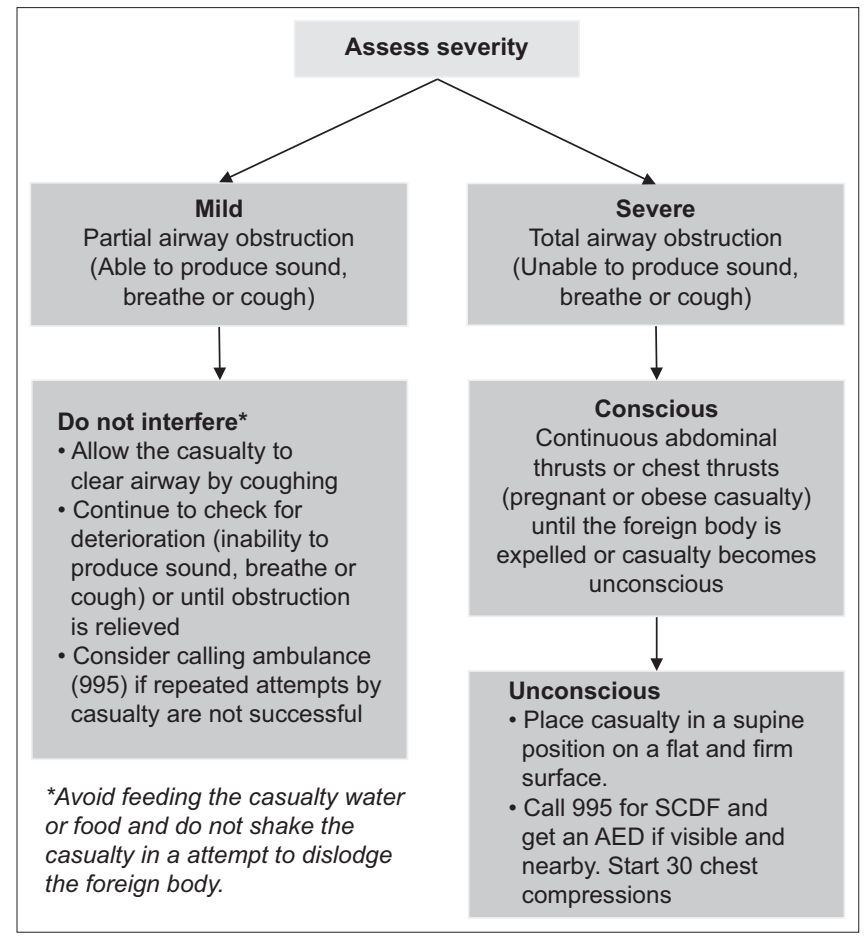

Fig. 5 Flowchart for conscious and unconscious foreign body airway obstruction. AED: automated external defibrillator; SCDF: Singapore Civil Defence Force

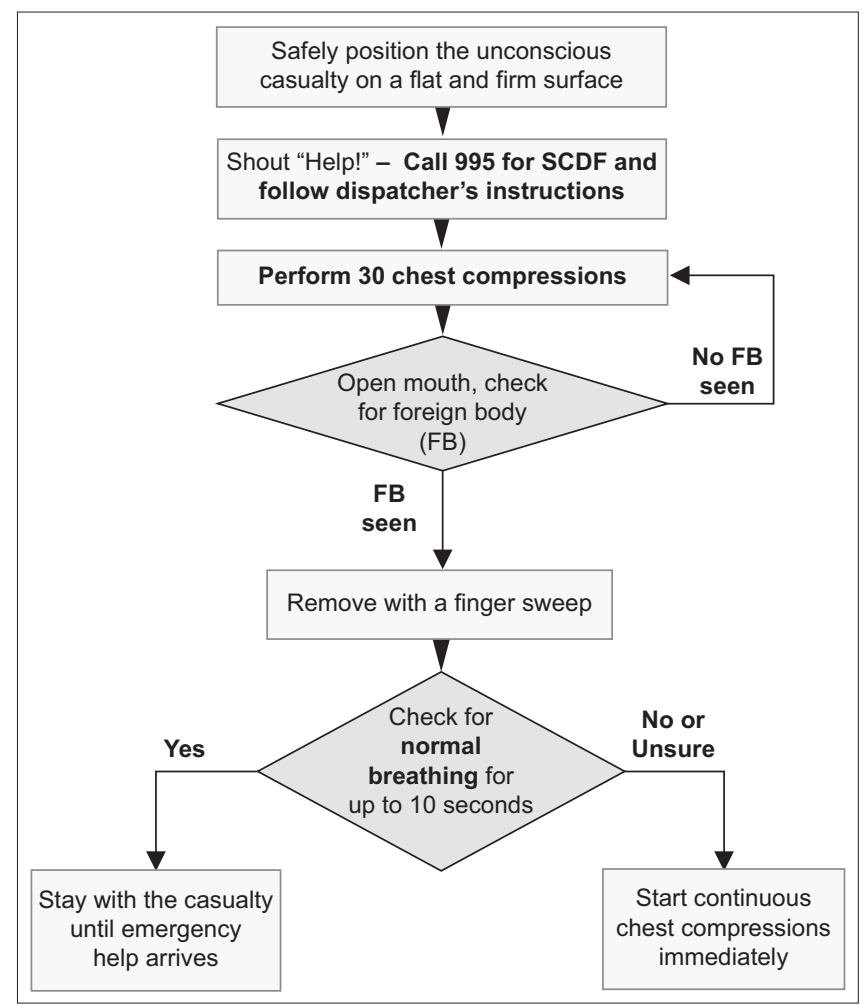

Fig. 6 Sequence for unconscious foreign body airway obstruction relief (lay responders). SCDF: Singapore Civil Defence Force

\section{RELIEF OF FOREIGN BODY AIRWAY OBSTRUCTION}

The recommended sequence of actions for relief of foreign body airway obstruction (FBAO) for conscious and unconscious casualties are as follows (Figs. 5-7). 


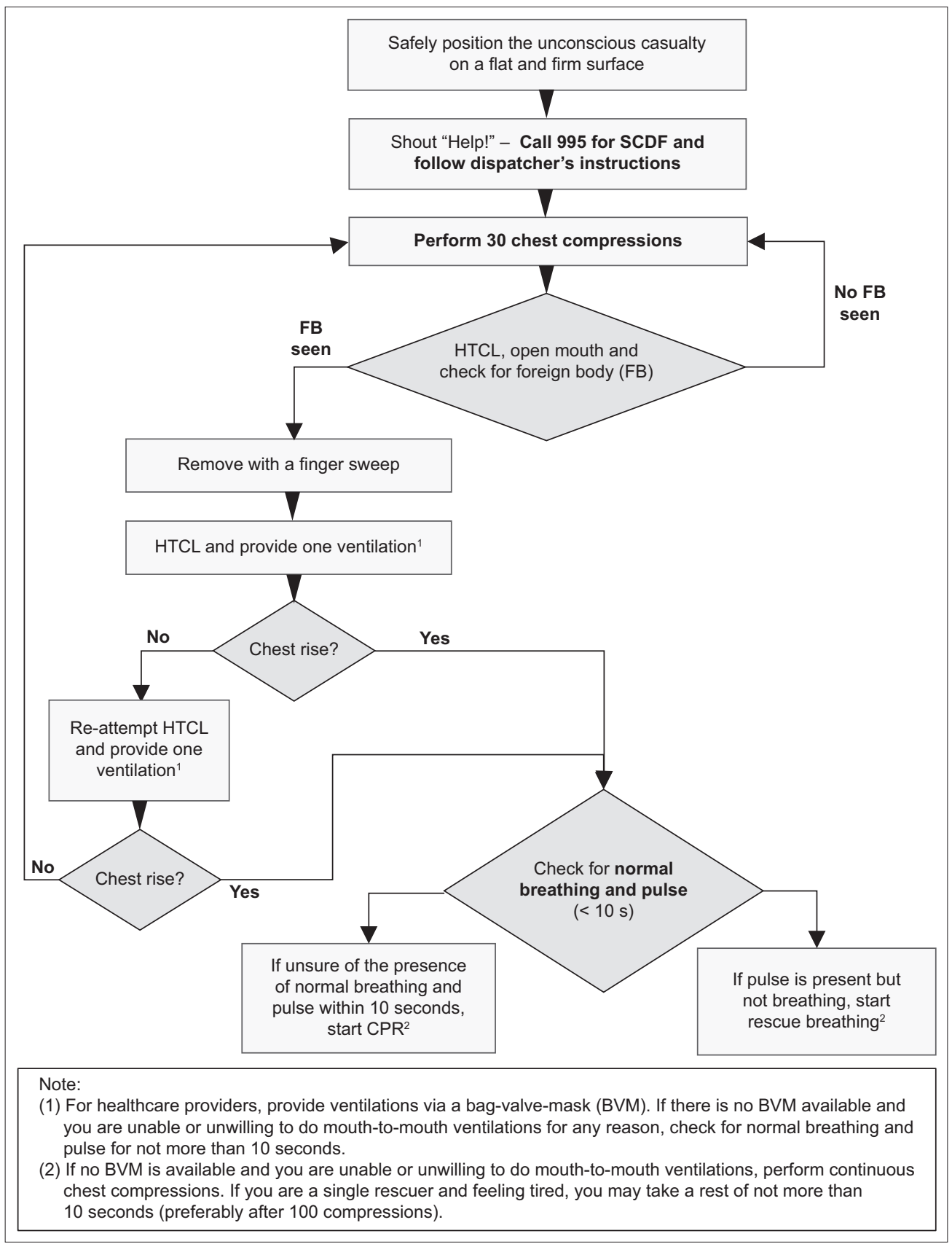

Fig. 7 Sequence for unconscious foreign body airway obstruction relief (healthcare providers). CPR: cardiopulmonary resuscitation; HTCL: head-tilt/chin-lift

1. Recognition of FBAO in a person who chokes while eating, with thumbs and fingers clutching the neck:

a) If the casualty is coughing effectively, this means that the airway is only partially obstructed. Do not interfere. Allow the casualty to cough and self-expel the foreign body.

b) In complete airway obstruction, the casualty is unable to speak, breathe or cough effectively, and this requires immediate action. The abdominal thrust is recommended for the relief of FBAO in responsive adults (aged > 12 years) and children (aged 1-12 years). For responsive casualties who are pregnant or obese, chest thrusts should be performed.

2. Perform continuous abdominal thrusts or chest thrusts (for pregnant or obese) until the foreign body is expelled or until the casualty becomes unconscious.
3. For the casualty who becomes unconscious, refer to the flowcharts in Figs. 6 and 7.

\section{CONCLUSION}

The most important interventions that will improve the survival outcome of cardiac arrest casualties are: early recognition; early CPR; early defibrillation; early activation of EMS; and early advanced life support. While there is minimal change in the 2021 SRFAC adult BCLS and AED guidelines, except that placing the casualty in the recovery position after ROSC is no longer recommended, the current guidelines continue to emphasise the importance of (a) treating casualties with gasping (no normal breathing) as if they are in cardiac arrest; (b) calling '995' early so that SCDF dispatchers can guide the caller in recognising cardiac arrest, give instructions for chest compression, and activate 
volunteer lay rescuers in the vicinity to bring a nearby AED to the scene and/or help with CPR; and (c) performing high-quality CPR.

\section{REFERENCES}

1. Olasveengen TM, Mancini ME, Perkins GD, et al; Adult Basic Life Suppor Collaborators. Adult basic life support: 2020 international consensus on cardiopulmonary resuscitation and emergency cardiovascular care science with treatment recommendations. Circulation 2020; 142(16 Suppl 1):S41-91.

2. Olasveengen TM, Mancini ME, Perkins GD, et al; Adult Basic Life Support Collaborators. Adult basic life support: international consensus on cardiopulmonary resuscitation and emergency cardiovascular care science with treatment recommendations. Resuscitation 2020; 156:A35-79.

3. Panchal AR, Bartos JA, Cabañas JG, et al. Part 3: adult basic and advanced life support: 2020 American Heart Association guidelines for cardiopulmonary resuscitation and emergency cardiovascular care. Circulation 2020; 142(16 Suppl 2):S366-468.

4. Olasveengen TM, Semeraro F, Ristagno G, et al. European Resuscitation Council guidelines 2021: basic life support. Resuscitation 2021; 161:98-114.

5. Ong GYK, Ngiam N, Tham LP, et al; Paediatric Subcommittee 2016-2021, Singapore Resuscitation and First Aid Council. Singapore Paediatric Resuscitation Guidelines 2021. Singapore Med J 2021; 62:372-89.

6. Bobrow BJ, Spaite DW, Berg RA, et al. Chest compression-only CPR by lay rescuers and survival from out-of-hospital cardiac arrest. JAMA 2010; 304:1447-54.

7. Mao DRH, Ee AZQ, Leong PWK, et al. Is your unconscious patient in cardiac arrest? A new protocol for telephonic diagnosis by emergency medical calltakers: a national study. Resuscitation 2020; 155:199-206.

8. Blewer AL, Ho AFW, Shahidah N, et al. Impact of bystander-focused public health interventions on cardiopulmonary resuscitation and survival: a cohort study. Lancet Public Health 2020; 5:e428-36.

9. Eberle B, Dick WF, Schneider T, et al. Checking the carotid pulse check: diagnostic accuracy of first responders in patients with and without a pulse. Resuscitation 1996; 33:107-16.

10. Teo WS, Anantharaman V, Lim SH. Update on resuscitation 2006. Singapore Med J 2007; 48:100-5.

11. Lim SH. Basic Cardiac Life Support: 2011 Singapore guidelines. Singapore Med J $2011 ; 52: 538-43$

12. Lim SH, Wee FC, Chee TS. Basic Cardiac Life Support: 2016 Singapore guidelines. Singapore Med J 2017; 58:347-53.

13. Stiell IG, Brown SP, Christenson J, et al; Resuscitation Outcomes Consortium (ROC) Investigators. What is the role of chest compression depth during outof-hospital cardiac arrest resuscitation? Crit Care Med 2012; 40:1192-8.

14. Hellevuo H, Sainio M, Nevalainen R, et al. Deeper chest compression - more complications for cardiac arrest patients? Resuscitation 2013; 84:760-5.

15. Hasegawa T, Daikoku R, Saito S, Saito Y. Relationship between weight of rescuer and quality of chest compression during cardiopulmonary resuscitation. J Physiol Anthropol 2014; 33:16.

16. Idris AH, Guffey D, Aufderheide TP, et al; Resuscitation Outcomes Consortium (ROC) Investigators. Relationship between chest compression rates and outcomes from cardiac arrest. Circulation 2012; 125:3004-12.

17. Kitamura T, Iwami T, Kawamura $\mathrm{T}$, et al; Implementation Working Group for All-Japan Utstein Registry of the Fire and Disaster Management Agency. Time-dependent effectiveness of chest compression-only and conventional cardiopulmonary resuscitation for out-of-hospital cardiac arrest of cardiac origin. Resuscitation 2011; 82:3-9.

18. Hasselqvist-Ax I, Riva G, Herlitz J, et al. Early cardiopulmonary resuscitation in out-of-hospital cardiac arrest. N Engl J Med 2015; 372:2307-15.

19. Caffrey SL, Willoughby PJ, Pepe PE, Becker LB. Public use of automated external defibrillators. N Engl J Med 2002; 347:1242-7.

20. Valenzuela TD, Roe DJ, Nochol G, et al. Outcomes of rapid defibrillation by security officers after cardiac arrest in casinos. N Engl J Med 2000; 343:1206-9.

21. Berg RA, Sanders AB, Kern KB, et al. Adverse hemodynamic effects of interrupting chest compressions for rescue breathing during cardiopulmonary resuscitation for ventricular fibrillation cardiac arrest. Circulation 2001; 104:2465-70.

22. Lim SH, Aw SJ, Cheong MA, et al. A randomised control trial to compare retention rates of two cardiopulmonary resuscitation instruction methods in the novice. Resuscitation 2016; 103:82-7.

23. Min MK, Yeom SR, Ryu JH, et al. A 10-s rest improves chest compression quality during hands-only cardiopulmonary resuscitation: a prospective, randomized crossover study using a mannequin model. Resuscitation 2013; 84:1279-84.

24. Singapore Resuscitation and First Aid Council. Basic Cardiac Life Support and Automated External Defibrillator (BCLS+AED) Provider Manual. Singapore; 2018. Available at: https://sera.sg/SRFAC-BCLSAED-and-CPRMTMAEDManual-2018.pdf. Accessed June 15, 2021.

25. Greif R, Lockey A, Breckwoldt J, et al. European Resuscitation Council Guidelines 2021: education for resuscitation. Resuscitation 2021; 161:388-407.

26. Nasiri E, Nasiri R. A comparison between over-the-head and lateral cardiopulmonary resuscitation with a single rescuer by bag-valve mask. Saudi J Anaesth 2014; 8:30-7.

27. Lott C, Truhláŕ A, Alfonzo A, et al. European Resuscitation Council Guidelines 2021: cardiac arrest in special circumstances. Resuscitation 2021; 161:152-219.

28. Singletary EM, Zideman D, Bendall JC, et al. 2020 international consensus on first aid science with treatment recommendations. Circulation 2020; 142(16 Suppl 1):S284-334.

29. Singletary EM, Zideman D, Bendall JC, et al. 2020 international consensus on first aid science with treatment recommendations. Resuscitation 2020; 156:A240-82.

30. Zarisfi F, Pek JH, Oh JHH, Loke JH, Lim SH. Singapore First Aid Guidelines 2021. Singapore Med J 2021; 62:427-32. 


\section{SINGAPORE MEDICAL COUNCIL CATEGORY 3B CME PROGRAMME} (Code SMJ 202108C)

Question 1. Regarding ventilation for an adult cardiac arrest casualty:

(a) If a rescuer is trained and willing to perform mouth-to-mouth (MTM) ventilation, the rescuer may proceed with MTM ventilation.

(b) If a rescuer is unwilling to perform MTM ventilation, the rescuer should not proceed with chest compressions and should continue to wait for help to arrive.

(c) The rescuer should provide two ventilations, one second per breath, with a tidal volume of $400-600 \mathrm{~mL}$ after every 30 chest compressions.

(d) The rescuer performs rescue breathing approximately once every three seconds.

Question 2. A 52-year-old woman was found unresponsive and not breathing in a ward.

(a) The preferred site for pulse check is the carotid artery.

(b) The depth of chest compression should be $4-6 \mathrm{~cm}$.

(c) The landmark for chest compressions is at the xiphoid process.

(d) The compression rate is 100-120 per minute.

Question 3. You are eating in a restaurant where a man appears to be in distress and choking. What should you do to relieve the foreign body obstructing the airway?

(a) Ask the casualty, "What did you eat?"

(b) If the casualty is coughing effectively, encourage him to continue to cough until the foreign body is expelled.

(c) If the casualty is unable to speak, breathe or cough, perform abdominal thrusts until the foreign body is expelled.

(d) If the foreign body cannot be expelled and the casualty becomes unconscious, commence rescue breathing.

Question 4. You are performing one-rescuer cardiopulmonary resuscitation (CPR) and another rescuer has brought the automated external defibrillator (AED) to you. Is the following true or false?

(a) The correct placement of the AED defibrillation pads on the casualty is one below the right clavicle and the other on the lateral side of the chest just below and to the left of the left nipple.

(b) Make sure that no one is touching the casualty when delivering the shock.

(c) The casualty lying on a very wet floor is not a contraindication for defibrillation.

(d) Chest compression should be continued when the AED is analysing the casualty's heart rhythm.

Question 5. An unresponsive casualty with no breathing has been found. Chest compressions have commenced and AED defibrillation pads have been applied. Is the following true or false?

(a) Place the casualty in the recovery position after the first shock.

(b) When AED prompts 'No-shock advised', disconnect the AED and continue to monitor the casualty until handover to medical personnel.

(c) When AED prompts 'No-shock advised', start chest compressions.

(d) Start chest compressions after a shock has been delivered.

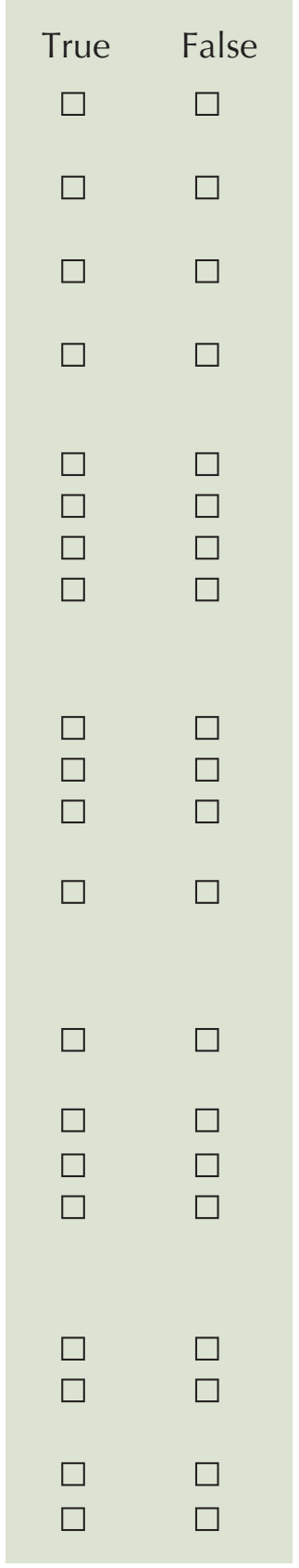

\section{Doctor's particulars:}

Name in full:

MCR no.:

Specialty:

Email:

\section{SUBMISSION INSTRUCTIONS:}

Visit the SMJ website: http://www.smj.org.sg/current-issue and select the appropriate quiz. You will be redirected to the SMA login page.

For SMA member: (1) Log in with your username and password (if you do not know your password, please click on 'Forgot your password?'). (2) Select your answers for each quiz and click 'Submit'.

For non-SMA member: (1) Create an SMJ CME account, or log in with your SMJ CME username and password (for returning users). (2) Make payment of SGD 21.40 (inclusive of $7 \%$ GST) via PayPal to access this month's quizzes. (3) Select your answers for each quiz and click 'Submit'.

RESULTS:

(1) Answers will be published online in the SMJ October 2021 issue. (2) The MCR numbers of successful candidates will be posted online at the SMJ website by 29 October 2021. (3) Passing mark is $60 \%$. No mark will be deducted for incorrect answers. (4) The SMJ editorial office will submit the list of successful candidates to the Singapore Medical Council. (5) One CME point is awarded for successful candidates. (6) SMC credits CME points according to the month of publication of the CME article (i.e. points awarded for a quiz published in the August 2021 issue will be credited for the month of August 2021, even if the deadline is in October 2021).

Deadline for submission (August 2021 SMJ 3B CME programme): 12 noon, 22 October 2021. 